\title{
2 Defensive plant responses induced by Nesidiocoris tenuis 3 (Hemiptera: Miridae) on tomato plants
}

\author{
4 Meritxell Pérez-Hedo - Pablo Urbaneja-Bernat •
}

5 Josep A. Jaques $\cdot$ Víctor Flors $\cdot$ Alberto Urbaneja

8 Abstract In the last decade, biological control programs 9 for greenhouse tomatoes and other crops have been successfully implemented using zoophytophagous plant bugs (Miridae), which can feed on both plant tissues and insect prey. It is well known that plants respond to herbivore attacks by releasing volatile compounds through diverse pathways triggered by phytohormones. These herbivoreinduced plant volatiles can alert neighboring plants, repel or attract herbivores, and attract natural enemies of these herbivores. Nevertheless, the possible benefits of induced plant responses by zoophytophagous predators that could add to their usefulness as biocontrol agents have not been studied until now. Here we show that the zoophytophagous predator Nesidiocoris tenuis activated abscisic acid and jasmonic acid (JA) signaling pathways in tomato plants, which made them less attractive to the whitefly Bemisia tabaci, a major tomato pest worldwide, and more attractive to the whitefly parasitoid, Encarsia formosa. We also found that intact tomato plants exposed to volatiles from $N$. tenuis-punctured plants activated the JA pathway, and as a

Communicated by D.C. Weber.

Electronic supplementary material The online version of this article (doi:10.1007/s10340-014-0640-0) contains supplementary material, which is available to authorized users.

M. Pérez-Hedo $(\bowtie) \cdot$ P. Urbaneja-Bernat · A. Urbaneja Centro de Protección Vegetal y Biotecnología, Instituto Valenciano de Investigaciones Agrarias (IVIA), Unidad de Entomología UJI-IVIA-CIB CSIC, Carretera de Moncada-Náquera Km. 4,5, 46113 Moncada, Valencia, Spain e-mail: meritxell_p@hotmail.com

\section{J. A. Jaques · V. Flors}

Unitat Associada d'Entomologia UJI-IVIA, Departament de Ciències Agràries i del Medi Natural, Universitat Jaume I, UJI, Campus del Riu Sec, 12071 Castelló de la Plana, Spain consequence, E. formosa was also attracted to these intact plants with activated defense systems. Thus, our results demonstrate that $N$. tenuis not only benefits tomato plants directly by entomophagy but also indirectly by phytophagy, which induces a physiological response in the tomato plant.

Keywords Bemisia tabaci Encarsia formosa . Induced plant responses · Biological control

Key message

We have proved that the zoophytophagous predator Nesidiocoris tenuis induces plant benefits directly by its entomophagy and also indirectly by its phytophagy, which induces the attraction of a whitefly parasitoid (Encarsia formosa) and antixenosis to the whitefly Bemisia tabaci. Furthermore, $N$. tenuis-punctured plants induce plant defenses in intact plants that result in attraction of $E$. formosa. Our results might be one reasonable explanation for the great success achieved by $N$. tenuis as a key biocontrol agent in tomatoes.

\section{Introduction}

In plants, arthropod herbivory activates different responses that are generally triggered by receptor complexes that recognize herbivore-associated elicitors (HAEs) and fatty acid-amino acid conjugates (FACs) (Bonaventure et al. 2011). Once the plant has identified an attack, it can respond through the activation of diverse signaling pathways. One set produces antibiotic and antixenotic compounds that exert a negative effect on the herbivore 28 29 30 31 32 (n) (3) 37

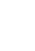
. (n) . . 
(Bennett and Wallsgrove 1994; Chen 2008) and systemic signals that warn other parts of the plant (Davis et al. 1991; Zhang and Baldwin 1997; Stratmann 2003). Another set causes the release of volatiles (so-called herbivore-induced plant volatiles or HIPVs) that play a double role in defense by priming both distal parts of the same plant and its neighbors (Frost et al. 2008) and attracting secondary consumers such as parasitoids and predators (Heil and Ton 2008) or repelling herbivores. Indeed, these HIPVs may increase plant productivity through a trophic cascade effect, which constitutes the basis of modern biological control science (Hairston et al. 1960; Oksanen et al. 1981).

Zoophytophagous predators are a special case of natural enemies (Coll and Guershon 2002). These omnivorous predators feed on plants and prey during the same developmental stage (Castañé et al. 2011). Interestingly, under certain conditions, omnivory has been demonstrated to be a stabilizing feature of complex natural systems (Kratina et al. 2012). Indeed, this plasticity facilitates the establishment of zoophytophagous predators in the crop prior to pest infestation and their conservation in periods of prey scarcity. As a result, crops in which zoophytophagous predators have been established become highly resilient to pest invasions (Ramakers and Rabasse 1995; Messelink et al. 2008; Lu et al. 2012). Zoophytophagous predators such as Miridae and Anthocoridae (Heteroptera) are becoming increasingly important for the biological control of important agricultural pests (Bueno et al. 2013; PérezHedo and Urbaneja 2014) even though they exploit plants for both feeding and oviposition (Coll 1996; Coll and Guershon 2002). They use their flexible stylets to extract liquid food from their prey and the plants on which they live. Females use their ovipositor to insert their eggs in the same plants. By wounding, these natural enemies can activate the same defense mechanisms as strict herbivores (Kessler and Baldwin 2004; Halitschke et al. 2011). Indeed, De Puysseleyr et al. (2011) demonstrated that Orius laevigatus (Fieber) (Heteroptera: Miridae), a widely used biological control agent for Thripidae, which are of economic importance, increased tomato (Solanum lycopersicum L.) resistance to pestiferous Frankliniella occidentalis (Pergande) (Thysanoptera: Thripidae) feeding by inducing jasmonic acid (JA)-mediated wound response during oviposition. However, the same authors noted that O. laevigatus is not naturally occurring or commercially used in tomato crops.

Among the different mirid bugs that can be found naturally feeding on tomato plants (Zappala et al. 2013), the cosmopolitan Nesidiocoris tenuis (Reuter) (Hemiptera:Miridae) has been extremely effective in controlling the invasive South American tomato pinworm Tuta absoluta (Meyrick) (Lepidoptera:Gelechiidae), an important tomato pest first detected in the Old World in 2007 (Desneux et al.
2010). Furthermore, the most threatening whitefly worldwide, Bemisia tabaci (Gennadius) (Hemiptera:Aleyrodidae), is also effectively controlled by this mirid bug (Calvo et al. 2012a; Urbaneja et al. 2012). Our research group has regularly observed over the last few years that the incidence of whiteflies, in particular B. tabaci, was very low in both protected and open-field tomato crops where $N$. tenuis was successfully established. At first, we attributed this result to active predation by $N$. tenuis, which typically lives in and feeds on the upper growing parts of tomato plants, on immature B. tabaci and, to a lesser extent, on B. tabaci adults (Calvo et al. 2009). However, we thought that predation alone could not explain the extremely low densities of B. tabaci adults landing on the apical parts of plants compared to conventional crops where pesticides were used. This observation led us to hypothesize that the presence of $N$. tenuis on plants could be the result of not only direct predation of this mirid on B. tabaci populations but also of indirect defense mechanisms, such as the attraction of other natural enemies, and the induction of plant defenses (antixenosis and antibiosis). However, to our knowledge, whether $N$. tenuis, which is not a strict herbivore, can activate plant responses and whether these responses can be an added benefit to its effectiveness as an arthropod predator remain unknown.

In this work, we hypothesized that tomato plants with $N$. tenuis were less attractive to the whitefly $B$. tabaci than plants without $N$. tenuis. Therefore, we studied whether the plant-feeding activity of $N$. tenuis could induce plant responses in tomato plants using hormonal profiling and gene-expression analysis of the main defensive signaling pathways. We also studied the role of selected phytohormones on host plant selection by the whitefly $B$. tabaci and the parasitoid Encarsia formosa (Gahan) (Hymenoptera: Aphelinidae), which is used commercially worldwide to control whiteflies in tomato crops (van Lenteren 2012) using hormone-deficient mutant tomato plants. Finally, because HIPVs can activate rapid defense responses in both distal plant parts and neighboring conspecific plants (Choh and Takabayashi 2006; Frost et al. 2008), we investigated whether HIPVs from $N$. tenuis-infested plants induce defensive responses in neighboring, uninfested tomato plants.

\section{Materials and methods}

Plant material and insects

S. lycopersicum (cv. Optima), abscisic acid (ABA)-defi155 cient (Sitiens) and jasmonic acid (JA)-deficient tomato mutants (def-1) and their respective near-isogenic wildtype (cvs. Rheinlands Rhum and Castlemart) parental lines
157

158

$\begin{array}{lll}\text { Journal : Large 10340 } & \text { Dispatch : 2-1-2015 } & \text { Pages : 12 } \\ \text { Article No. : } \mathbf{6 4 0} & \square \text { LE } & \square \text { TYPESET } \\ \text { MS Code : PEST-D-14-00368 } & \boldsymbol{\sim}_{\text {CP }} & \checkmark \text { DISK }\end{array}$


were used to determine the responses of B. tabaci and the whitefly parasitoid $E$. formosa to the different experimental treatments described below. Plants were used for experiments at 6 weeks of age, when they had seven to eight fully expanded leaves. All plant genotypes were germinated in soil, and 2 weeks after germination, the seedlings were individually transferred to pots and maintained at $25 \pm 2{ }^{\circ} \mathrm{C}$ and high relative humidity $(>60 \%)$ under a 16:8 h L:D photoperiod.

B. tabaci, E. formosa and N. tenuis individuals were directly provided from the mass rearings of Koppert Biological Systems, S.L. (Águilas, Murcia, Spain). E. formosa pupae were isolated in a petri dish $(9 \mathrm{~cm}$ diameter) where a small drop of honey was provided on the sides of the dish as a food source. Adult females less than 2 days old were used in all trials. In the case of B. tabaci, newly emerged adults were released on four tomato plants placed in a $60 \times 60 \times 60-\mathrm{cm}$ plastic cage (BugDorm-2; MegaView Science Co., Ltd.; Taichung, Taiwan) for 48 h. Female adults less than 5 days old were collected from those plants and used in all trials.

\section{Y-tube bioassays}

The behavioral responses of B. tabaci and E. formosa females to plant volatiles were investigated in a Y-tube olfactometer (Analytical Research Systems, Gainesville, FL) consisting of a 2.4-cm-diameter Y-shaped glass tube with a $13.5-\mathrm{cm}$-long base and two $5.75-\mathrm{cm}$-long arms. The base of the Y-tube was connected to an air pump that produced a unidirectional airflow at $150 \mathrm{ml} / \mathrm{min}$ from the arms to the base of the tube. The arms were connected via plastic tubes to two identical glass jars (5-1 volume), each of which contained a test odor source. Each odor source vial was connected to a flow meter and a water filter. Four 60-cm-long fluorescent tubes (OSRAM, L18 W/765, OSRAM GmbH, Germany) were positioned $40 \mathrm{~cm}$ above the arms. The light intensity over the Y-tube was measured with a ceptometer (LP-80 AccuPAR, Decagon Devices, Inc., Pullman, WA) at 2,516 lux. The environmental conditions in the Y-tube experiments were $23 \pm 2{ }^{\circ} \mathrm{C}$ and $60 \pm 10 \%$ RH.

Each female was observed until she had walked at least $3 \mathrm{~cm}$ up one of the side arms or until $15 \mathrm{~min}$ had elapsed. Females that did not choose a side arm within $15 \mathrm{~min}$ were considered to be 'non-responders' and were not included in the subsequent data analysis. Each individual was used only once. After five individual females had been tested, the olfactometer arms were flipped around $\left(180^{\circ}\right)$ to minimize the spatial effect on arm choice. After ten females had been bioassayed, the olfactometer setup was rinsed with soap, water and acetone and then air dried.
To confirm our initial hypothesis that tomato plants with $N$. tenuis were less attractive to the whitefly $B$. tabaci than plants without $N$. tenuis, two different two-choice experiments were conducted. The first took place in the Y-tube olfactometer described above. A combination of the following experimental treatments was assayed: (1) intact plants, (2) N. tenuis-bagged plants, which were tomato plants holding two double-layer gauze bags (to prevent plant feeding) containing two $N$. tenuis pairs each, and (3) $N$. tenuis-punctured plants, which were obtained by enclosing four intact tomato plants in a $60 \times 60 \times 60$-cm plastic cage (BugDorm-2; MegaView Science Co., Ltd.; Taichung, Taiwan) in which $100 \mathrm{~N}$. tenuis had been previously introduced for $24 \mathrm{~h}$. All $N$. tenuis specimens were removed from $N$. tenuis-punctured plants before being subjected to this Y-tube choice assay.

The second choice experiment consisted of releasing $100 \mathrm{~B}$. tabaci in the middle of a $60 \times 60 \times 60-\mathrm{cm}$ plastic cage (BugDorm-2, MegaView Science Co., Ltd.; Taichung, Taiwan) containing three intact plants and three plants that had each been previously in contact with two pairs of $N$. tenuis for 7 days. $N$. tenuis-punctured plants were obtained simulating the standard commercial method of $N$. tenuis release in which $0.25-0.5 N$. tenuis pairs per plant are inoculated in the nursery for 7 days before transplanting to the greenhouse (Calvo et al. 2012a; Urbaneja et al. 2012). Twenty-four hours after the release of $B$. tabaci, the number of whitefly individuals per plant was counted. The experiment was replicated five times. This experiment was conducted in a glasshouse located at the Instituto Valenciano de Investigaciones Agrarias IVIA (Moncada, Valencia, Spain). The climatic conditions were $25 \pm 2{ }^{\circ} \mathrm{C}$ and $65 \pm 10 \% \mathrm{RH}$ and a natural photoperiod (approximately 14L:10D).

Phytohormone analysis

Because HIPV release is the result of a signaling cascade in response to an herbivore attack that triggers the activation of diverse defensive signaling pathways controlled by phytohormones, we determined the levels of different phytohormones in the apical part (apical bud with tender developing stem and leaves) of $N$. tenuis-punctured tomato plants (plants exposed to $25 \mathrm{~N}$. tenuis adults for $24 \mathrm{~h}$ prior to the assay) compared to intact plants. The hormones ABA, indole-3-acetic acid (IAA), salicylic acid (SA), JA, 12-oxo-phytodienoic acid (OPDA) and JA-isoleucine (JAIle) were analyzed by ultra-performance liquid chromatography coupled to mass spectrometry (UPLC-MS) (Flors et al. 2008; Forcat et al. 2008). Fresh material from intact and $N$. tenuis-punctured plants was frozen in liquid 
nitrogen and lyophilized. Before extraction, a mixture of internal standards containing $100 \mathrm{ng}$ d6ABA, $100 \mathrm{ng}$ d6IAA and $100 \mathrm{ng}$ dhJA was added. Dry tissue $(0.05 \mathrm{~g})$ was immediately homogenized in $2.5 \mathrm{ml}$ of ultrapure water.

After centrifugation $(5,000 \times \mathrm{g}, 40 \mathrm{~min})$, the supernatant was recovered and adjusted to $\mathrm{pH} 2.8$ with $6 \%$ acetic acid and subsequently partitioned twice against an equal volume of diethyl ether. The aqueous phase was discarded, and the organic fraction was evaporated in a Speed Vacuum Concentrator (Eppendorf; http://www.eppendorf.com) at room temperature. The solid residue was re-suspended in $1 \mathrm{ml}$ of a methanol/water (10:90) solution and filtered through a 0.22 $\mu \mathrm{m}$ cellulose acetate filter (13 mm pk/100 TR-200430. Olimpeak. Teknokroma, Barcelona, Spain). A $20-\mu 1$ aliquot of this solution was then directly injected into the HPLC system. Analyses were carried out using a Waters Alliance 2690 HPLC system (Waters, http://www.waters.com/) with a Kromasil reversed phase column (100 $2 \mathrm{~mm}$ i.d.; $5 \mathrm{~lm}$; Scharlabl, http://www.scharlab.es). The chromatographic system was interfaced with a Quatro LC (quadrupole-hexapole-quadrupole) mass spectrometer (Micromass; http:// www.micromass.co.uk). MASSLYNX NT software version 4.1 (Micromass) was used to process the quantitative data from calibration standards and the plant samples. The calibration curves were obtained by using solutions containing increasing amounts of ABA, JA, SA, IAA and OPDA commercial standards (Sigma-Aldrich, http://www.sigmaaldrich.com/) and JA-Ile (kindly provided by Edward Farmer, University of Lausanne, Switzerland) and a fixed amount of the corresponding internal standard.

ABA- and JA-induced responses

Because the ABA pathway is mainly activated in response to abiotic stresses such as water stress or desiccation (Kahn et al. 1993; Maskin et al. 2001; Ramirez et al. 2009), and this is a symptom that $N$. tenuis produces in tomato plants (Calvo et al. 2009), we decided to explore the effect of ABA-induced responses on the preference of the herbivore B. tabaci. For this purpose, the ABA-deficient tomato mutant Sitiens and its near-isogenic wild-type (wt) parental line were assessed (Asselbergh et al. 2007; Rodriguez et al. 2010) in the laboratory using an olfactometer. We also compared the response of whiteflies to the volatiles emitted from intact $w t$ tomato plants and intact $w t$ tomato plants treated with exogenous ABA. Ten milliliters of $100 \mu \mathrm{M}$ ABA solution (Sigma, St Louis, MO, USA) per plant was applied as a soil drench to 6-week-old plants to mimic the response induced by $N$. tenuis-punctured plants. Twentyfour hours later, plants were used for the Y-tube experiments. Additionally, the ASRI (abscisic acid stress ripening protein) transcriptional response of the apical part of intact $w t$ and $N$. tenuis-punctured tomato plants (var. Rheinlands) was obtained. Total RNA was extracted from the leaves of three plants, converted to cDNA and subjected to quantitative RT-PCR analysis (see below for more details).

Because many previous studies have demonstrated that the JA signaling pathway is involved in the attraction of natural enemies (Erb et al. 2012), we decided to investigate whether the JA signaling pathway induced by the plantfeeding behavior of $N$. tenuis might be attractive to the whitefly parasitoid $E$. formosa. For this purpose, we used the JA-deficient tomato mutant def- 1 and its near-isogenic wild-type (wt) parental line (Vicedo et al. 2009; O'Donnell et al. 2003) with or without $N$. tenuis feeding punctures. Additionally, the PIN2 (a JA-regulated defense protein) transcriptional response of the apical part of intact $w t$ and $N$. tenuis-punctured tomato plants (var. Castlemart) was determined. Total RNA was extracted from the leaves of three plants, converted to cDNA and subjected to quantitative RT-PCR analysis (see below for more details).

Induction of defensive responses in neighboring plants

The preference of B. tabaci and E. formosa for plants that had not been in contact with the mirid but had been placed in close contact with $N$. tenuis-punctured plants or intact plants was investigated in the laboratory using an olfactometer. We placed tomato plants that had been exposed to $N$. tenuis the day prior together with tomato plants that had not been exposed to $N$. tenuis (hereafter HIPV-exposed plants) for $24 \mathrm{~h}$ following the methodology described above. Five independent replicates were performed. The ASR1 (abscisic acid stress ripening protein) and PIN2 (a JA-regulated defense protein) transcriptional response of the apical part of intact, HIPV-exposed and N. tenuispunctured tomato plants was determined. Total RNA was extracted from the apical part of the plants, converted to cDNA and subjected to quantitative RT-PCR analysis (see the following section for more details).

Quantification of plant gene expression

Transcription of the genes ASR1 and PIN2, a proteinase inhibitor, was analyzed (Lopez-Raez et al. 2010). The apical part of the tomato plants (as explained above) was ground in liquid nitrogen, and a portion was used for RNA extraction. Total RNA $(1.5 \mu \mathrm{g})$ extracted by the Plant RNA Kit (Omega Bio-Tek Inc., Doraville, GA, USA) was treated with RNase-free DNase (Promega Corp., Madison, WI, USA) to eliminate genomic DNA contamination. The RT reaction was performed by adding $2 \mu \mathrm{l}$ of RT buffer, $2 \mu \mathrm{l}$ of $5 \mathrm{mM}$ dNTP, $2 \mu \mathrm{l}$ of $10 \mu \mathrm{M}$ Oligo(dT) 15 primer [Promega, Oligo(dT) 15 Primer], $1 \mu \mathrm{l}$ of $10 \mathrm{U} / \mu \mathrm{l}$ RNase inhibitor (Promega RNasin RNase inhibitor) and $1 \mu \mathrm{l}$ of 
Omniscript reverse transcriptase (Qiagen, Barcelona, Spain). The reaction mixture was incubated at $37{ }^{\circ} \mathrm{C}$ for $60 \mathrm{~min}$. Complementary DNA from the RT reaction, diluted ten-fold, was used for qPCR. Forward and reverse primers $(0.3 \mu \mathrm{M})$ were added to $12.5 \mu \mathrm{l}$ of PCR SYBR reaction buffer and $2 \mu \mathrm{l}$ of cDNA, then brought to $25 \mu \mathrm{l}$ total volume by Milli-Q sterile water (Takara Bio, Kyoto, Japan). Quantitative PCR was carried out using the Smart Cycler II (Cepheid, Sunnyvale, CA USA) sequence detector with standard PCR conditions. There were differences in the cycle numbers during the linear amplification phase for different samples. The data were transformed with the formula $2 \Delta \mathrm{Ct}$. RT-qPCR analysis was performed at least three times using sets of cDNA samples of independent experiments. Expression of EF1 (elongation factor-1) was used as a standard control gene for normalization. The nucleotide sequences of the gene-specific primers are described in Table S1.

\section{Data analyses}

$\chi^{2}$ Tests were used to test the hypothesis that the distribution of side-arm choices between pairs of odors deviated from a null model where odor sources were chosen with equal frequency. Females that did not make a choice were excluded from the statistical analysis. The results were expressed as the mean $\pm \mathrm{SE}$. Significant differences $(P<0.05)$ were determined with a one-tailed Student's $t$ test performed in a pairwise manner for the concentration of each phytohormone. One-way ANOVA followed by a comparison of means (Tukey's test) was applied to identify differences in the transcriptional responses of the ASR 1 and $P I N 2$ genes in the apical parts of intact, induced and $N$. tenuis-feeding punctured tomato plants.

\section{Results}

$N$. tenuis feeding influences $B$. tabaci plant selection

Whitefly females were attracted to the odor of tomato plants over clean air $\left(\chi^{2}=18.29, P<0.0001\right.$; Fig. 1a) in a Y-tube olfactometer. Plants experiencing $N$. tenuis feeding activity proved to be less attractive to $B$. tabaci than intact plants $\left(\chi^{2}=6.25, P=0.0124\right.$; Fig. 1a). The repellence effect of $N$. tenuis per se was discarded based on the results of the first test where whitefly females were offered intact tomato plants that were either empty or contained two couples of $N$. tenuis each in two double-layer gauze bags (to prevent plant feeding $)\left(\chi^{2}=1.724, P=0.1892\right.$; Fig. 1a), indicating that whiteflies were not able to detect the mere presence of
$N$. tenuis on plants. Furthermore, intact plants on which $N$. tenuis was bagged were preferred relative to $N$. tenuispunctured plants $\left(\chi^{2}=16.20, P<0.0001\right.$; Fig. 1a).

An additional semi-field choice test simulating commercial $N$. tenuis releases in tomato crops confirmed that whiteflies avoided $N$. tenuis-punctured tomato plants $(t=5.724, P<0.0001$; Fig. 1b).

$N$. tenuis plant feeding modifies the plant phytohormone profile

The endogenous levels of $\mathrm{ABA}(t=3.459, P=0.0086$; Fig. 2a) and the components of the JA pathway 12-oxophytodienoic acid (OPDA, a precursor of JA; Fig. 2b) and isoleucine conjugate of JA (JA-Ile, the bioactive form of JA; Fig. 2c) were higher in the apical part of $N$. tenuispunctured plants $(t=2.472 ; P=0.0386$ and $t=3.936$; $P=0.0043$ for OPDA and JA-Ile, respectively). Despite the trend of increased JA concentration in $N$. tenuispunctured plants, the difference was not significant $(t=1.410, P=0.1962$; Fig. $2 \mathrm{~d})$, probably as a consequence of its conversion to other metabolic sinks such as JA-Ile (Fig. 2c). The levels of salicylic acid (SA) were similar in both treatments $(t=0.9849, \quad P=0.1760$; Fig. 2f). In contrast, the indole-3-acetic acid (IAA) content was lower in $N$. tenuis-punctured plants $(t=2.662$, $P=0.0287$; Fig. 2e). Therefore, alteration of the phytohormone profiling of tomato plants by $N$. tenuis activity was demonstrated.

ABA-induced repellence on whiteflies

Given a choice between intact $w t$ plants and $N$. tenuispunctured $w t$ plants, $B$. tabaci chose the plant not in contact with the mirid $\left(\chi^{2}=22.22, \quad P<0.001\right.$; Fig. $\left.3 a\right)$, as expected from the results above. The ABA mutant tomato plants were preferred over the intact $w t$ plants by whiteflies $\left(\chi^{2}=10.29, P=0.0013\right.$; Fig. 3a). Accordingly, whiteflies did not show a significant preference $\left(\chi^{2}=0.2857\right.$, $P=0.5930$; Fig. 3a) for ABA-mutant plants that were or were not exposed to mirids. The ABA-mutant tomato plants with $N$. tenuis feeding punctures were preferred over $N$. tenuis-punctured $w t$ plants $\left(\chi^{2}=18.00, P<0.001\right.$; Fig. 3a). A strongly significant $B$. tabaci preference was observed for plants that were not watered with exogenous ABA $\left(\chi^{2}=30.41, P<0.001 ;\right.$ Fig. $\left.3 a\right)$. Transcriptional analysis showing that $N$. tenuis-punctured plants expressed higher levels of the ABA-responsive ASRl gene than intact plants confirmed that the insect-infested plants contained higher levels of the phytohormone ABA $(t=2.228$, $P=0.0449$; Fig. 3b).
432

433

434

435

436

437

438

439

440

441

442

443

444

445

446

447

448

449

450

451

$\begin{array}{lll}\text { Journal : Large 10340 } & \text { Dispatch : 2-1-2015 } & \text { Pages : 12 } \\ \text { Article No. : } \mathbf{6 4 0} & \square \text { LE } & \square \text { TYPESET } \\ \text { MS Code : PEST-D-14-00368 } & \sim_{\text {CP }} & \checkmark \text { DISK }\end{array}$




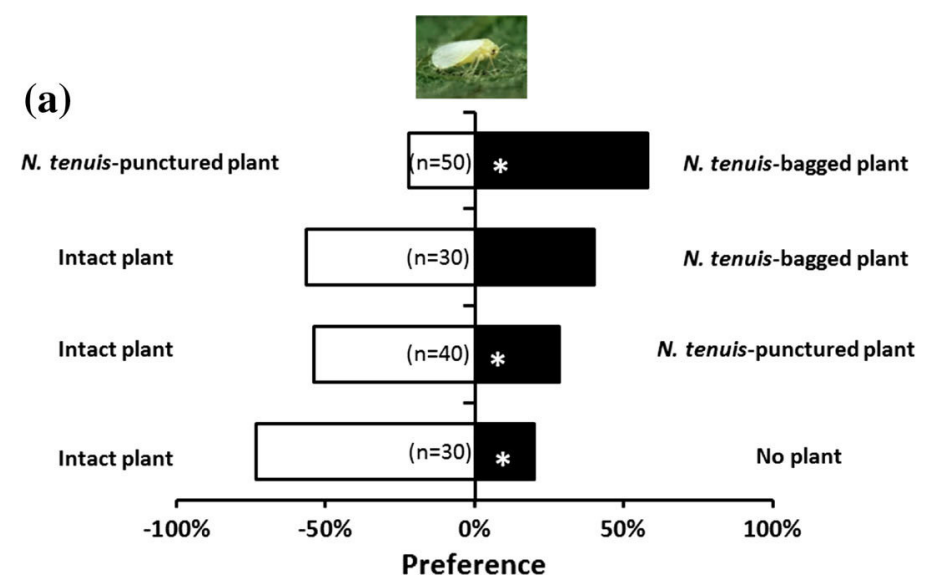

(b)

Fig. 1 Bemisia tabaci plant selection mediated by Nesidiocoris tenuis. a Response of the herbivore B. tabaci females in a Y-tube olfactometer when exposed to intact tomato plants, intact tomato plants containing two pairs of the zoophytophagous $N$. tenuis in two double-layer gauze bags (to prevent plant feeding and oviposition) $(N$. tenuis-bagged plant) or tomato plants that had been exposed to $25 \mathrm{~N}$. tenuis adults for $24 \mathrm{~h}$ prior to the assay (N. tenuis-punctured plants).

452

453

454

455

456

457

458

459

460

461

462

463

464

465

466

467

468

469

470

471

472

473

474

475

476

477

478

479

480
JA-induced attraction of the parasitoid Encarsia formosa

The wasp E. formosa significantly chose $N$. tenuis-punctured $w t$ plants or intact $w t$ plants (Fig. $4 \mathrm{a} ; \chi^{2}=30.41$, $P<0.001)$ over JA-deficient mutant plants whether in contact with the mirids $\left(\chi^{2}=30.41, P<0.001\right.$; Fig. $\left.4 a\right)$ or not $\left(\chi^{2}=30.41, P<0.001\right.$; Fig. 4 a). To confirm that $N$. tenuis-punctured plants had higher JA expression, the PIN2 transcriptional response of the apical part of both types of tomato plants was analyzed $(t=5.112, \quad P=0.035$; Fig. 4b). This clear effect showed that $N$. tenuis activity resulted in attraction of the parasitoid E. formosa.

\section{$N$. tenuis-punctured plants induce plant defenses} in intact plants

The whitefly B. tabaci did not show any preference between HIPV-exposed plants or intact plants $\left(\chi^{2}=0.00, P=1\right.$; Fig. 5a). However, the parasitoid E. formosa was significantly attracted to HIPV-exposed tomato plants relative to intact ones $\left(\chi^{2}=14.00, P=0.0002\right.$; Fig. 5a). To confirm the hypothesis that exposure to HIPVs from $N$. tenuis-damaged plants induces defenses of intact plants, we measured the transcriptional response of the genes ASRI and PIN2 as a measure of ABA and JA expression, respectively, for intact, HIPV-exposed and $N$. tenuis-punctured plants as in the above experiments. The two studied genes, ASRI ( $F=19.33, P=0.0009$; Fig. 5b) and PIN2 ( $F=20.79, P=0.0004$; Fig. 5c), were upregulated when the tomato plant was exposed to HIPVs from $N$. tenuis-damaged plants, as demonstrated above. More interestingly, and in accordance with the results obtained in the
Significant differences based on a $\chi^{2}$ test are marked with $(*)$ $(P<0.001)$. b Number of $B$. tabaci adults per plant $(\mathrm{X} \pm \mathrm{SE})$ captured $24 \mathrm{~h}$ after releasing $100 \mathrm{~B}$. tabaci in the center of a circle in which three intact plants and three $N$. tenuis-punctured plants were evenly distributed inside a cage. Significant differences based on a $t$ test are marked with $(*)(P<0.001)$

olfactometer, the amounts of these two transcripts of defenserelated genes were different in HIPV-exposed plants compared to $N$. tenuis-punctured plants. The induction of defenses had no effect on ASRI expression compared with intact plants, while PIN2 reached the same levels in HIPV-exposed and $N$. tenuis-punctured plants, confirming the potential of HIPVs from $N$. tenuis-damaged plants to activate plant defenses in neighboring, undamaged plants via JA, resulting in attraction of parasitoids.

\section{Discussion}

During the last decade, biological control programs using mirids (Calvo et al. 2012a), which can feed on both plant tissues and insect prey (Castañé et al. 2011), have been effectively implemented in greenhouse tomatoes and other crops. To date, the success of these predators has been mainly attributed to their efficient predation of a wide range of important pests (Urbaneja et al. 2009; Calvo et al. 2012b; Pérez-Hedo and Urbaneja 2014) and to their phytophagy (Calvo et al. 2009), which allows them to become established prior to pest appearance and to maintain their populations in periods of prey scarcity. Remarkably, $N$. tenuis was formerly considered a tomato pest because of feeding-based damage such as necrotic rings in apical stems (Raman and Sanjayan 1984; Calvo et al. 2009) when prey is scarce. However, thanks to proper management (exhaustive monitoring and adoption of corrective measures when needed), this predator has shifted from being considered a pest to becoming a key biological control agent for successful pest management (Calvo et al. 2012a).

\begin{tabular}{|l|lll|}
\hline & Journal : Large 10340 & Dispatch : 2-1-2015 & Pages : 12 \\
Article No. : $\mathbf{6 4 0}$ & $\square$ LE & $\square$ TYPESET \\
MS Code : PEST-D-14-00368 & $\boldsymbol{\sim}_{\mathrm{CP}}$ & $\checkmark_{\mathrm{DISK}}$ \\
\hline
\end{tabular}



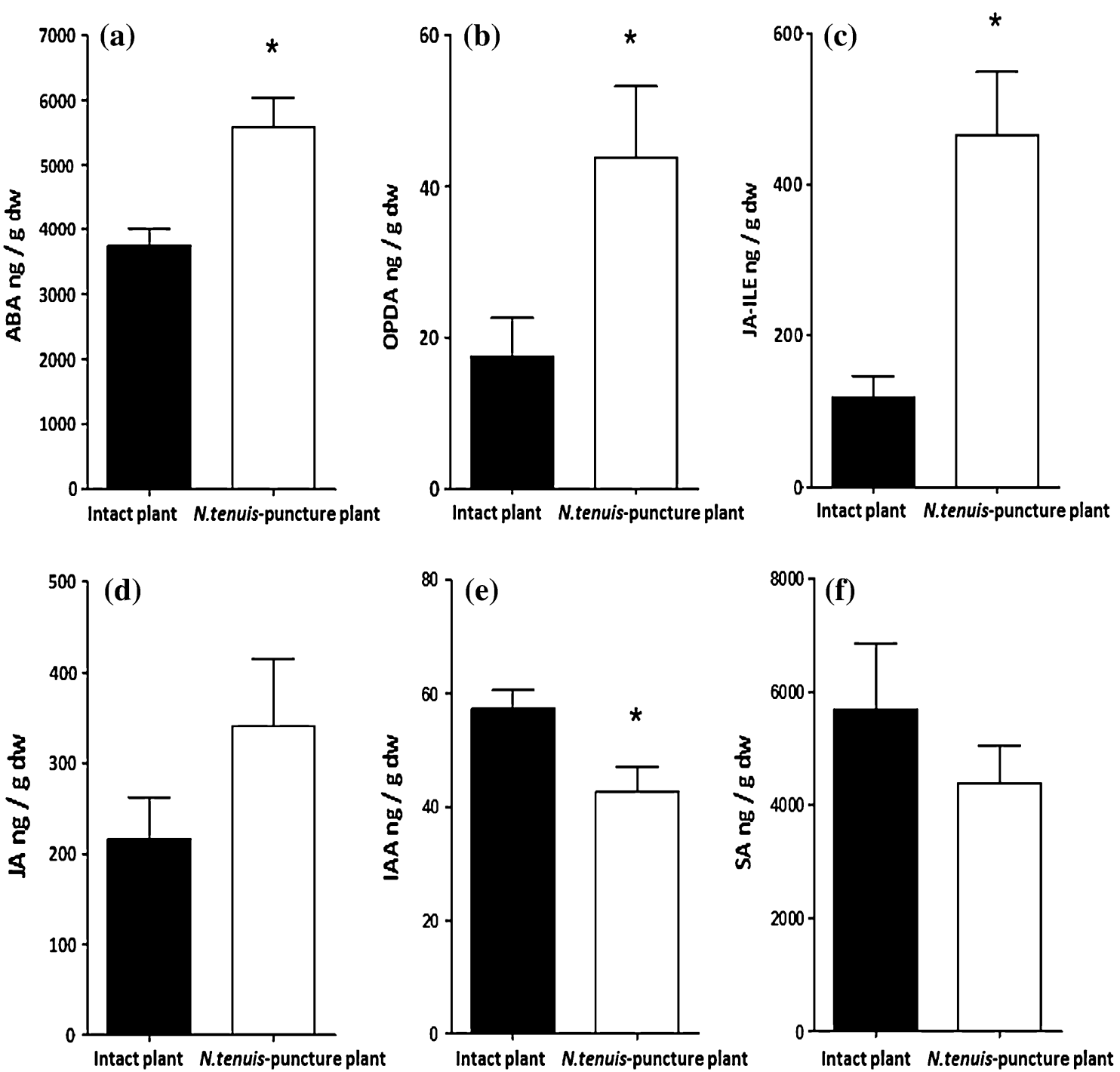

Fig. 2 Effect of Nesidiocoris tenuis injury on different phytohormone levels of a ABA, b OPDA, c JA-Ile d JA, e IAA and $\mathbf{f}$ SA in the apical part of tomato plants. The results shown are mean hormone

levels of five independent analyses \pm SE $(n=5)$. Significant differences based on a $t$ test are marked with $(*)(P<0.05)$

Our results (see Fig. 6 for a graphical summary) confirm that the activity of a zoophytophagous insect induces a physiological response in plants (Kessler and Baldwin 2004; Halitschke et al. 2011) similar to that induced by strictly phytophagous mirid species (Rodriguez-Saona et al. 2002). Specifically, the insect triggers synthesis of HIPVs, which make plants less attractive to herbivores, attract natural enemies and induce defenses in neighboring plants, which undoubtedly strongly contribute to the success of these predators as invertebrate biological control agents.

Our results confirmed that the plant-feeding behavior of $N$. tenuis significantly changed the phytohormone levels of tomato plants. The zoophytophagous predator activates the ABA, IAA and JA signaling pathways. However, levels of the phytohormone SA, which has been considered an herbivore repellent in many previous studies (Erb et al. 2012), were not significantly different between $N$. tenuis-punctured plants and intact plants. Wei et al. (2014) demonstrated that there are antagonistic effects of SA-mediated responses on JA-mediated responses and vice versa. In addition, the dose and timing of phytohormone levels may affect the behavioral responses of an herbivore. Therefore, the crosstalk between SA- and JA-dependent defense responses to plant feeding by $N$. tenuis deserves further research.

Although ABA involvement in multiple physiological processes in response to abiotic stresses and pathogen attacks has been shown (Leung and Giraudat 1998; Erb et al. 2012), its relationship to herbivory is still poorly

\begin{tabular}{|c|c|c|c|}
\hline & Journal : Large 10340 & Dispatch : 2-1-2015 & Pages: 12 \\
\hline & $\begin{array}{l}\text { Article No. : } 640 \\
\text { MS Code : } \quad \text { PEST-D-14-00368 }\end{array}$ & $\begin{array}{l}\square \\
\boldsymbol{\mho}_{\mathrm{CP}}^{\mathrm{LE}} \\
\end{array}$ & $\begin{array}{l}q \text { TYPESET } \\
\mho_{\text {DISK }}\end{array}$ \\
\hline
\end{tabular}




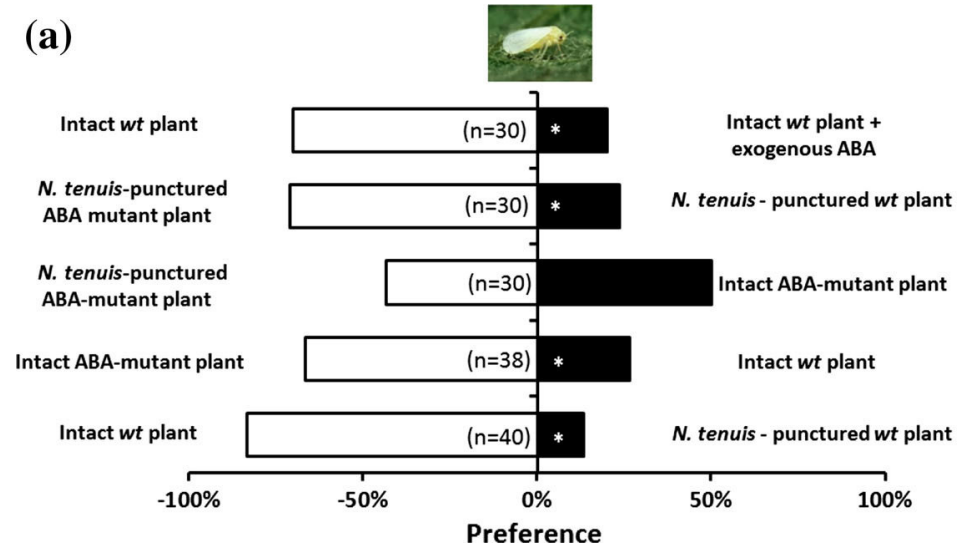

(b)

Fig. 3 ABA-induced non-attraction of whiteflies. a Response of the herbivore Bemisia tabaci females in a Y-tube olfactometer when exposed to ABA-deficient mutant tomato plants or their near isogenic wild type (wt plant), which were with the zoophytophagous Nesidiocoris tenuis (N. tenuis-punctured plants) or without (intact plants) contact with $N$. tenuis or wt plant irrigated with $10 \mathrm{ml}$ of $100 \mu \mathrm{M}$ ABA $24 \mathrm{~h}$ before the assay. Significant differences using a $\chi^{2}$ test are marked with $\left(^{*}\right)(P<0.001)$. b Transcriptional response of the apical part of intact $w t$ and $N$. tenuis-punctured tomato plants (var. Rheinlands) for the ASR1 gene, which is ABA responsive. Transcript levels were normalized to the expression of EF1 $\alpha$ measured in the same sample. Data are presented as a mean of three independent analyses of transcript expression relative to the housekeeping gene plants $\pm \mathrm{SE}(n=3)$. Significant differences using a $t$ test are marked with $(*)(P<0.05)$

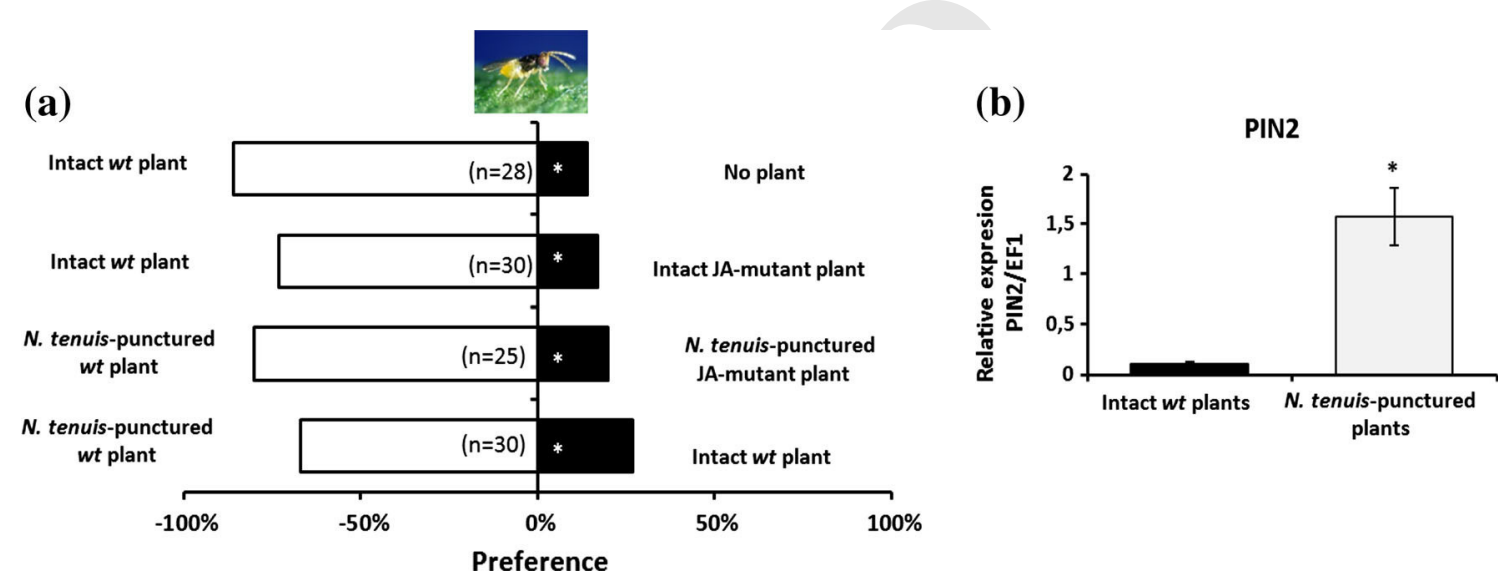

Fig. 4 JA-induced attraction to the parasitoid Encarsia formosa. a Response of E. formosa females in a Y-tube olfactometer when exposed to JA-mutant tomato plants or their near isogenic wild type (wt plants) in contact with the zoophytophagous Nesidiocoris tenuis (N. tenuis-punctured plants) or not in contact (intact plants) with $N$. tenuis. Significant differences using a $\chi^{2}$ test are marked with $(*)$

documented (Bodenhausen and Reymond 2007). Our results show that $B$. tabaci did not reject induced tomato plants where the ABA pathway, as opposed to the JA pathway, had not been altered. We have demonstrated that an intact ABA pathway, which is the pathway activated by $N$. tenuis activity, is needed to make the plant less attractive to whiteflies, while JA is not directly related to this antixenotic response. The ABA pathway is mainly activated in response to abiotic stresses such as water stress or desiccation (Kahn et al. 1993; Maskin et al. 2001; Ramirez
$(P<0.001)$. b $P I N 2$ transcriptional response, which is JA responsive, in the apical part of intact $w t$ and $N$. tenuis-punctured tomato plants (var. Castlemart). The data are presented as the mean of three independent analyses of transcript expression relative to housekeeping gene plants $\pm \mathrm{SE}(n=3)$. Significant differences based on a $t$ test are marked with $(*)(P<0.05)$

et al. 2009). Therefore, the ABA pathway signaling activated by $N$. tenuis could simply be the response of the tomato plant to water-content reduction (and logically other supplementary nutrients) caused by feeding of $N$. tenuis, which is mostly detectable in the form of necrotic rings in the apical stems of the plant (Castañé et al. 2011). Therefore, it might be reasonable that whiteflies recognize plants emitting HIPVs triggered through the ABA pathway as stressed plants and consequently as less suitable for the progeny. Another possible explanation for $B$. tabaci

\begin{tabular}{|l|lll|}
\hline Journal : Large 10340 & Dispatch : 2-1-2015 & Pages : 12 \\
Article No. : $\mathbf{6 4 0}$ & $\square$ LE & $\square$ TYPESET \\
MS Code : PEST-D-14-00368 & $\sim_{\text {CP }}$ & $\checkmark$ DISK \\
\hline
\end{tabular}



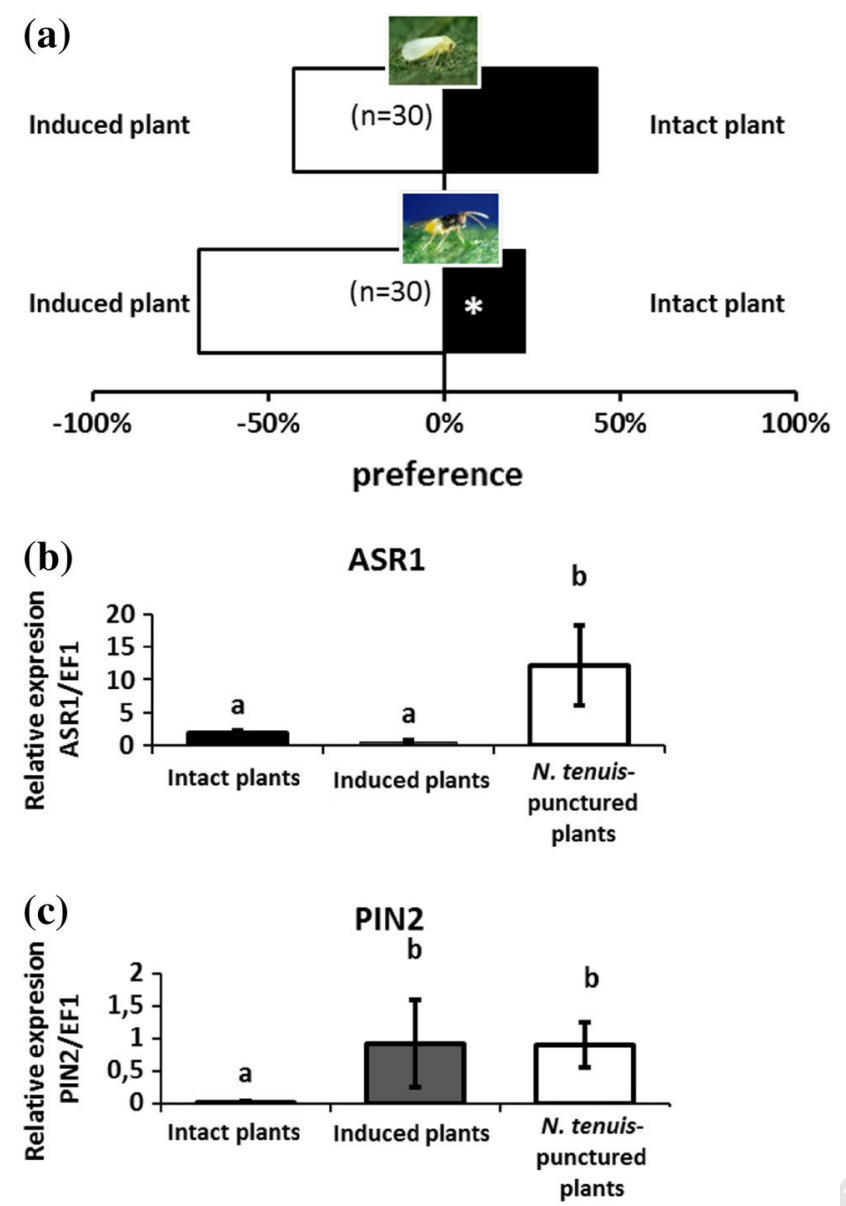

Fig. 5 Nesidiocoris tenuis-punctured plant induces plant defenses in intact plants. a Response of the herbivore Bemisia tabaci and the parasitoid Encarsia formosa females in a Y-tube olfactometer when exposed to intact and induced (plants that had not been in contact with the mirid but had been placed in close contact with $N$. tenuis-punctured plants for $24 \mathrm{~h}$ ) tomato plants. Significant differences based on a $\chi^{2}$ test are marked with $(*)(P<0.001)$. b and c ASRl (b) and PIN2 (c) transcriptional responses, which are $\mathrm{ABA}$ and JA responsive, respectively, in the apical part of intact, induced and $N$. tenuispunctured tomato plants. Data are presented as the mean of four independent analyses of transcript expression relative to a housekeeping gene $\pm \mathrm{SD}(n=4)$. Different letters over the bars indicate significant differences $(P<0.05)$ based on Tukey comparisons

560 rejection is that heavily $B$. tabaci-infested tomato plants 561 could induce a plant response similar to that caused by $N$. 562 tenuis, i.e., activation of the ABA pathway, given that both 563 hemipterans have piercing-sucking mouthparts and feed on 564 vascular bundles, particularly phloem tissue and the 565 neighboring parenchyma cells (Raman and Sanjayan 1984; 566 Walker 2010). Thus, whiteflies could also identify plants 567 emitting HIPVs triggered by the ABA pathway signaling as 568 plants already highly populated by conspecific whiteflies, 569 which would impair the successful development of their 570 progeny through increased competition. However, further 571 research is required to distinguish between these two 57 A02 hypotheses.
The endogenous JA levels of the tomato plant strongly affected the response of the parasitoid E. formosa. This parasitoid significantly exhibited a preference for $N$. tenuis-punctured plants, which have higher JA expression relative to intact plants. Previous studies have demonstrated the role of JA in indirect defense mechanisms, which results in attraction of natural enemies to plants (Heil 2008; Dicke 2009). The reason why this whitefly parasitoid is capable of detecting $N$. tenuis-punctured plants is unlikely to be related to the presence of the zoophytophagous predator, given that on those plants the parasitoid would encounter a lower whitefly population. Therefore, we believe that the parasitoid is able to relate the presence of HIPVs triggered by the activation of JA pathway with a high presence of suitable hosts on these plants, which induces physiological defense responses as we hypothesized above.

We have observed that tomato plants activate defense systems because of the wounding by $N$. tenuis. It is known that some plants appear to respond to environmental cues that reliably indicate an increased probability of attack before they actually experience an herbivore or pathogen (Frost et al. 2008; Muroi et al. 2011; Shiojiri et al. 2012). We initially wondered whether HIPVs from $N$. tenuisinfested plants could induce plant defenses in neighboring, uninfested tomato plants and therefore could activate the mechanisms of avoidance of B. tabaci and attraction of $E$. formosa. As noted earlier, our results show that $B$. tabaci did not reject HIPV-exposed plants, while the parasitoid was strongly attracted by HIPV-exposed plants. Further research is needed to better understand the variables associated with this interesting phenomenon both from a basic point of view (why only the JA pathway is activated) and for application in crop protection practices (how long the plant's response to HIPVs is effective).

The apical IAA content was also increased in N. tenuispunctured plants. This phytohormone coordinates development in plants (Sachs and Thimann 1967). Therefore, we hypothesize that $N$. tenuis feeding on the apex, which may affect plant growth, partially blocks auxin-mediated apical dominance. However, whether IAA is mediating an effect (repellence or attraction) on herbivores or natural enemies needs further research.

In summary, we have proven that the zoophytophagous predator $N$. tenuis induces plant benefits not only directly by its entomophagy but also indirectly by its phytophagy through an increase in the attraction of the whitefly parasitoid E. formosa (an indirect mechanism of defense) and antixenosis to $B$. tabaci (a direct mechanism of resistance). Furthermore, chemical attraction of a natural enemy could be induced in neighboring plants. Our results might be one reasonable explanation for the great success achieved by $N$. tenuis as a key biocontrol agent in tomatoes.

$\begin{array}{lll}\text { Journal : Large 10340 } & \text { Dispatch : 2-1-2015 } & \text { Pages : 12 } \\ \text { Article No. : } \mathbf{6 4 0} & \square \text { LE } & \square \text { TYPESET } \\ \text { MS Code : PEST-D-14-00368 } & \sim_{\text {CP }} & \checkmark \text { DISK }\end{array}$




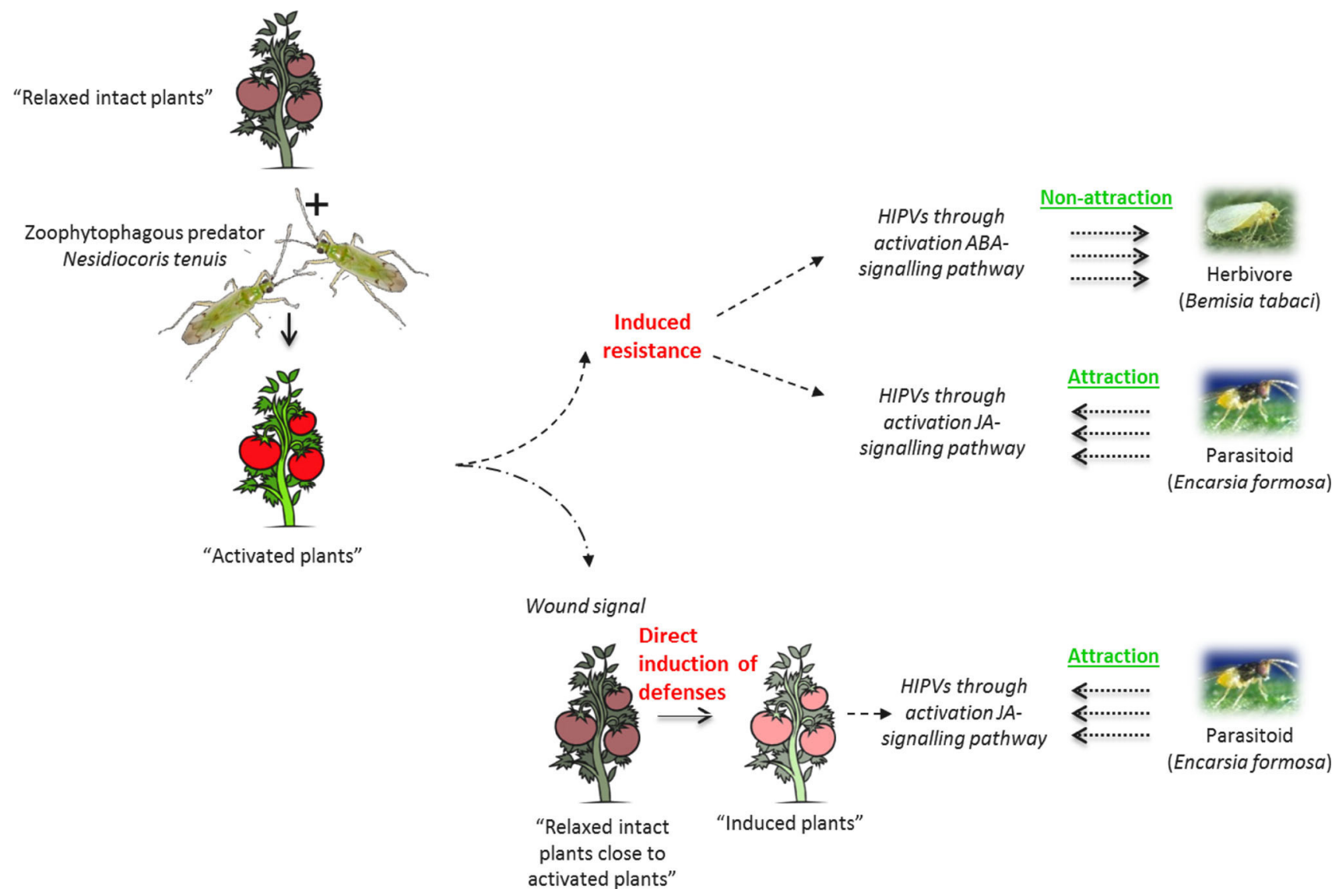

Fig. 6 A conceptual model of plant benefits indirectly caused by the zoophytophagous predator Nesidiocoris tenuis. At the top left of the flow chart, a relaxed tomato plant is induced by $N$. tenuis feeding. $N$. tenuis feeding activated abscisic acid (ABA) and jasmonic acid (JA)signaling pathways in tomato plants, which resulted in a non-

\section{Author contribution statement}

MP-H and AU designed the research. All authors per- preference effect on the whitefly $B$. tabaci and in attraction of the whitefly parasitoid Encarsia formosa. Some of the chemical changes in the punctured plant may act as wound signals to undamaged adjacent tomato plants. The JA pathway is activated in induced tomato plants, which results in attraction to the parasitoid $E$. formosa

\section{References}

Asselbergh B, Curvers K, Franca SC, Audenaert K, Vuylsteke M, Van Breusegem F, Hofte M (2007) Resistance to Botrytis cinerea in sitiens, an abscisic acid-deficient tomato mutant, involves timely production of hydrogen peroxide and cell wall modifications in the epidermis. Plant Physiol 144:1863-1877

Bennett RN, Wallsgrove RM (1994) Secondary metabolites in plant defense-mechanisms. New Phytol 127:617-633

Bodenhausen N, Reymond P (2007) Signaling pathways controlling induced resistance to insect herbivores in Arabidopsis. Mol Plant Microbe Interact 20:1406-1420

Bonaventure G, VanDoorn A, Baldwin IT (2011) Herbivore-associated elicitors: FAC signaling and metabolism. Trends Plant Sci 16:294-299

Bueno VHP, van Lenteren JC, Lins JC, Calixto AM, Montes FC, Silva DB, Santiago LD, Pérez LM (2013) New records of Tuta absoluta (Meyrick) (Lepidoptera:Gelechiidae) predation by Brazilian Hemipteran predatory bugs. J App Entomol 137:29-34

Calvo J, Blockmans K, Stansly PA, Urbaneja A (2009) Predation by Nesidiocoris tenuis on Bemisia tabaci and injury to tomato. Biocontrol 54:237-246

\begin{tabular}{|l|lll|}
\hline & Journal : Large 10340 & Dispatch : 2-1-2015 & Pages : 12 \\
Article No. : $\mathbf{6 4 0}$ & $\square$ LE & $\square$ TYPESET \\
MS Code : PEST-D-14-00368 & $\boldsymbol{\sim}_{\mathrm{CP}}$ & $\checkmark_{\mathrm{DISK}}$ \\
\hline
\end{tabular}


Calvo FJ, Lorente MJ, Stansly PA, Belda JE (2012a) Preplant release of Nesidiocoris tenuis and supplementary tactics for control of Tuta absoluta and Bemisa tabaci in greenhouse tomato. Entomol Exp Appl 143:111-119

Calvo FJ, Soriano J, Bolckmans K, Belda JE (2012b) A successful method for whitefly and Tuta absoluta control in tomato. Evaluation after two years of application in practice. IOBC/ WPRS Bull 80:237-244

Castañé C, Arnó J, Gabarra R, Alomar O (2011) Plant damage to vegetable crops by zoophytophagous mirid predators. Biol Control 59:22-29

Chen MS (2008) Inducible direct plant defense against insect herbivores: a review. Insect Sci 15:101-114

Choh Y, Takabayashi J (2006) Herbivore-induced extrafloral nectar production in lima bean plants enhanced by previous exposure to volatiles from infested conspecifics. J Chem Ecol 32:2073-2077

Coll M (1996) Feeding and ovipositing on plants by an omnivorous insect predator. Oecologia 105:214-220

Coll M, Guershon M (2002) Omnivory in terrestrial arthropods: mixing plant and prey diets. Annu Rev Entomol 47:267-297

Davis JM, Gordon MP, Smit BA (1991) Assimilate movement dictates remote sites of wound-induced gene-expression in poplar leaves. Proc Natl Acad Sci USA 88:2393-2396

De Puysseleyr V, Hofte M, De Clercq P (2011) Ovipositing Orius laevigatus increase tomato resistance against Frankliniella occidentalis feeding by inducing the wound response. ArthPlant Int 5:71-80

Desneux N, Wajnberg E, Wyckhuys K, Burgio G, Arpaia S, NarváezVasquez C, González-Cabrera J, Catalán-Ruescas D, Tabone E, Frandon J, Pizzol J, Poncet C, Cabello T, Urbaneja A (2010) Biological invasion of European tomato crops by Tuta absoluta: ecology, geographic expansion and prospects for biological control. J Pest Sci 83:197-215

Dicke M (2009) Behavioural and community ecology of plants that cry for help. Plant Cell Environ 32:654-665

Erb M, Meldau S, Howe GA (2012) Role of phytohormones in insectspecific plant reactions. Trends Plant Sci 17(5):250-259

Flors V, Ton J, van Doorn R, Jakab G, Garcia-Agustin P, MauchMani B (2008) Interplay between JA, SA and ABA signalling during basal and induced resistance against Pseudomonas syringae and Alternaria brassicicola. Plant J 54:81-92

Forcat S, Bennett MH, Mansfield JW, Grant MR (2008) A rapid and robust method for simultaneously measuring changes in the phytohormones $\mathrm{ABA}, \mathrm{JA}$ and $\mathrm{SA}$ in plants following biotic and abiotic stress. Plant Methods 4:16

Frost CJ, Mescher MC, Carlson JE, De Moraes CM (2008) Plant defense priming against herbivores: getting ready for a different battle. Plant Physiol 146:818-824

Hairston NG, Smith FE, Slobodkin LB (1960) Community structure, population control, and competition. Am Nat 94:421-425

Halitschke R, Hamilton JG, Kessler A (2011) Herbivore-specific elicitation of photosynthesis by mirid bug salivary excretions in the wild tobacco Nicotiana attenuata. New Phytol 191:528-535

Heil M (2008) Indirect defence via tritrophic interactions. New Phytol 178:41-61

Heil M, Ton J (2008) Long-distance signalling in plant defence. Trends Plant Sci 13:264-272

Kahn TL, Fender SE, Bray EA, Oconnell MA (1993) Characterization of expression of drought and abscisic acid-regulated tomato genes in the drought-resistant species Lycopersicon pennellii. Plant Physiol 103:597-605

Kessler A, Baldwin I (2004) Herbivore-induced plant vaccination. Part I. The orchestration of plant defenses in nature and their fitness consequences in the wild tobacco Nicotiana attenuata. The Plant J 38:639-649
Kratina P, LeCraw RM, Ingram T, Anholt BR (2012) Stability and persistence of food webs with omnivory: is there a general pattern? Ecosphere 3:50

Leung J, Giraudat J (1998) Abscisic acid signal transduction. Annu Rev Plant Phys 49:199-222

Lopez-Raez JA, Verhage A, Fernandez I, Garcia JM, Azcon-Aguilar C, Flors V, Pozo MJ (2010) Hormonal and transcriptional profiles highlight common and differential host responses to arbuscular mycorrhizal fungi and the regulation of the oxylipin pathway. J Exp Bot 61:2589-2601

Lu YH, Wu KM, Jiang YY, Guo YY, Desneux N (2012) Widespread adoption of $\mathrm{Bt}$ cotton and insecticide decrease promotes biocontrol services. Nature 487:362-365

Maskin L, Gudesblat GE, Moreno JE, Carrari FO, Frankel N, Sambade A, Rossi M, Iusem ND (2001) Differential expression of the members of the Asr gene family in tomato (Lycopersicon esculentum). Plant Sci 161:739-746

Messelink GJ, van Maanen R, van Steenpaal SEF, Janssen A (2008) Biological control of thrips and whiteflies by a shared predator: two pests are better than one. Biol Control 44:372-379

Muroi A, Ramadan A, Nishihara M, Yamamoto M, Ozawa R, Takabayashi J, Arimura G (2011) The composite effect of transgenic plant volatiles for acquired immunity to herbivory caused by inter-plant communications. PLoS One 6:e24594

O’Donnell PJ, Schmelz E, Block A, Miersch O, Wasternack C, Jones JB, Klee HJ (2003) Multiple hormones act sequentially to mediate a susceptible tomato pathogen defense response. Plant Physiol 133:1181-1189

Oksanen L, Fretwell SD, Arruda J, Niemela P (1981) Exploitation ecosystems in gradients of primary productivity. Am Nat 118:240-261

Pérez-Hedo M, Urbaneja A (2014) Prospects for predatory mirid bugs as biocontrol agents of aphids in sweet peppers. J Pest Sci. doi:10.1007/s10340-014-0587-1

Ramakers PMJ, Rabasse JM (1995) Integrated pest management in protected cultivation. Novel approaches to integrated pest management. CRC Press, Florida

Raman K, Sanjayan KP (1984) Histology and Histopathology of the Feeding Lesions by Cyrtopeltis Tenuis Reut (Hemiptera, Miridae) on Lycopersicon esculentum Mill (Solanaceae). Proc Indian Acad Sci Anim Sci 93:543-547

Ramirez V, Coego A, Lopez A, Agorio A, Flors V, Vera P (2009) Drought tolerance in Arabidopsis is controlled by the OCP3 disease resistance regulator. Plant J 58:578-591

Rodriguez JAM, Morcillo RL, Vierheilig H, Ocampo JA, LudwigMuller J, Garrido JMG (2010) Mycorrhization of the notabilis and sitiens tomato mutants in relation to abscisic acid and ethylene contents. J Plant Physiol 167:606-613

Rodriguez-Saona C, Crafts-Brandner SJ, Williams L III, Paré PW (2002) Lygus hesperus feeding and salivary gland extracts induce volatile emissions in plants. J Chem Ecol 28:1733-1747

Sachs T, Thimann V (1967) Role of auxins and cytokinins in release of buds from dominance. Am J Bot 54(1):136-144

Shiojiri K, Ozawa R, Matsui K, Sabelis MW, Takabayashi J (2012) Intermittent exposure to traces of green leaf volatiles triggers a plant response. Sci Rep 2:378

Stratmann JW (2003) Long distance run in the wound responsejasmonic acid is pulling ahead. Trends Plant Sci 8:247-250

Urbaneja A, Monton H, Molla O (2009) Suitability of the tomato borer Tuta absoluta as prey for Macrolophus pygmaeus and Nesidiocoris tenuis. J Appl Entomol 133:292-296

Urbaneja A, Gonzalez-Cabrera J, Arno J, Gabarra R (2012) Prospects for the biological control of Tuta absoluta in tomatoes of the Mediterranean basin. Pest Manag Sci 68:1215-1222 
van Lenteren JC (2012) The state of commercial augmentative biological control: plenty of natural enemies, but a frustrating lack of uptake. Biocontrol 57:1-20

Vicedo B, Flors V, Leyva MD, Finiti I, Kravchuk Z, Real MD, Garcia-Agustin P, Gonzalez-Bosch C (2009) Hexanoic acidinduced resistance against Botrytis cinerea in tomato plants. Mol Plant Microbe Interact 22:1455-1465

Walker GPP, TM, Freeman, TP (2010) Life history, functional anatomy, feeding and mating behavior. In: Stanlsy PAN, S.E. (ed) Bemisia: bionomics and management of global pest. Springer Dordrecht

Wei JN, van Loon JJA, Gols R, Menzel TR, Li N, Kang L, Dicke M (2014) Reciprocal crosstalk between jasmonate and salicylate defence-signalling pathways modulates plant volatile emission and herbivore host-selection behaviour. J Exp Bot 65:3289-3298
Zappala L, Biondi A, Alma A, Al-Jboory IJ, Arno J, Bayram A, Chailleux A, El-Arnaouty A, Gerling D, Guenaoui Y, ShaltielHarpaz L, Siscaro G, Stavrinides M, Tavella L, Aznar RV, Urbaneja A, Desneux N (2013) Natural enemies of the South American moth, Tuta absoluta, in Europe, North Africa and Middle East, and their potential use in pest control strategies. J Pest Sci 86:635-647

Zhang ZP, Baldwin IT (1997) Transport of [2-C-14] jasmonic acid from leaves to roots mimics wound-induced changes in endogenous jasmonic acid pools in Nicotiana sylvestris. Planta 203:436-441 